\title{
Sentidos de Vitória/Derrota para os Pais Segundo Atletas do Alto Rendimento
}

Feelings of Victory/Defeat in Parents of High-Yield Athletes

Sentidos de Victoria/Derrota para los Padres Según los Atletas de Alto Rendimiento

Isabela Amblard \& Fatima Leite Cruz

Universidade Federal de Pernambuco

http://dx.doi.org/10.1590/1982-3703000132014 
Resumo: Este estudo compreendeu as representações sociais da vitória/derrota para os pais segundo atletas-adolescentes do esporte de alto rendimento, na cidade do Recife. A adolescência é compreendida a partir da Psicologia Social-histórica, e o embasamento teórico-metodológico da Teoria das Representações Sociais abordou os sujeitos em diferentes contextos socioculturais, lugares de pertencimento, experiências, crenças, saberes e sentimentos compartilhados. Adotou-se a perspectiva pluri metodológica com variados recursos de coleta e análise progressiva de dados. Participaram 101 atletas-adolescentes do esporte de alto rendimento, nas modalidades natação e vôlei. Os instrumentos utilizados foram questionários de associação livre e entrevistas semidirigidas. $\mathrm{Na}$ análise dos dados, o software EVOC e as técnicas de análise temática de conteúdo de Bardin. Identificamos as representações de vitória para os pais, nas dimensões: pessoal e motivacional, e afetivo-emocional e, nas representações sociais da derrota para os pais, além destas, a dimensão técnica. O sentido de vitória para os pais apareceu ampliado: o contexto esportivo, a escolarização, e o crescimento pessoal e profissional na vida. A derrota para os pais é representada como oportunidade de aprendizado e superação para o atleta-adolescente, porém, eles mostraram que necessitam do apoio afetivo de sua família para lidar com a autoculpabilização nas situações de fracasso.

Palavras-chave: Representações sociais. Esporte de alto rendimento. Vitória. Derrota.

Abstract: This study examined the social representations of victory and defeat held by parents of teenage athletes who participated in a high performance sports in the city of Recife. The developmental stage of adolescence is understood based on sociohistorical psychology, while the social representations theory constituted the frame of reference for approaching individuals from different social-cultural contexts, places, experiences, beliefs, knowledge, and shared feelings. A multi-methodological orientation was employed with a wide range of resources for the collection and progressive analysis of data. In this study, participants involved 101 teenager athletes, who participated in a high performance sport, either swimming or volleyball. The tools utilized included a free association questionnaire and semistructured interviews. EVOC 2000 and Bardin's thematic content analysis were used for data analysis. Representations of victory were identified from the parents for the following dimensions: personal and motivational and affective-emotional. In addition to those two dimensions, the technical dimension was also identified for the parental representation of defeat. The victory meaning for parents was not restricted just to the sport area, it was extended to other contexts such as education level, professional and personal growth. The value of defeat for parents was represented as an opportunity for learning and overcoming situations to the teenage athlete. However, they also showed the need for affective support from their families to deal with self-blame in the event of failure.

Keywords: Social representations. High performance sport. Victory. Defeat.

Resumen: Este estudio comprendió las representaciones sociales de la victoria/derrota para los padres según adolescentes atletas de deporte de alto rendimiento en la ciudad de Recife. La Adolescencia comprendida a partir de la Psicología Socio Histórica y la base teórico- metodológica de la Teoría de las Representaciones Sociales abordó los sujetos en diferentes contextos socioculturales, lugares de origen, experiencias, creencias, saberes y sentimientos compartidos. Se adoptó una perspectiva plurimetodológica con variados recursos de recolección de análisis progresivo de datos. Participaron 101 atletas adolescentes de deporte de alto rendimiento en las modalidades de natación y volibol. Los instrumentos utilizados fueron cuestionarios de asociación libre y entrevistas semi-dirigidas. En el análisis de los datos, se usó el software EVOC y las técnicas de análisis temático del contenido de Bardin. Identificamos las representaciones de victoria para los padres en las dimensiones: personalmotivacional y afectivo-emocional y, en las representaciones sociales de la derrota para los padres, además de éstas, se consideró la dimensión técnica. El sentido de victoria para los padres apareció ampliado: el contexto deportivo, la escolarización y el crecimiento personal y profesional en la vida. La derrota para los padres es representada como oportunidad de aprendizaje y superación para el atleta adolescente, sin embargo, ellos demostraron que necesitan apoyo afectivo de su familia para lidiar con la auto culpabilidad en las situaciones de fracaso.

Palabras clave: Representaciones sociales. Deporte de alto rendimiento. Victoria. Derrota. 


\section{Introdução}

Neste estudo, investigamos as representações sociais (RS) de vitória/derrota para os pais, compartilhadas por atletas-adolescentes do esporte de alto rendimento. Os termos vitória/ derrota são apresentados em contraste, pois se relacionam à díade inclusão/exclusão, presentes no cotidiano dos atletas envolvidos na prática competitiva, sobretudo, no esporte de alto rendimento que "[...] traz consigo os propósitos de novos êxitos esportivos, a vitória sobre adversários nos mesmos códigos, e é exercido sob regras preestabelecidas pelos organismos internacionais de cada modalidade [...]" (Tubino, 1992, p. 36).

A capacidade de superação se mostra essencial aos atletas do alto rendimento e, nesta direção, os treinamentos são exaustivos, diários, visando a preparação física e técnica que levem à vitória, o que resulta na escassez de tempo para os estudos e o lazer. Nestas condições, há rebatimentos nos sujeitos e impactos nas famílias, principalmente, no contexto da sociedade seletiva e classificatória, cujo fator protetivo dos pais volta-se para que o filho tenha sucesso. Questionamos: quais os sentidos compartilhados pelos atletas-adolescentes do esporte de alto rendimento acerca de como os seus pais lidam com suas vitórias/derrotas?

Por muito tempo, os adolescentes foram tipificados pela Psicologia Clássica, padronizados como portadores de uma síndrome de "anormalidades" temporárias, na passagem para a vida adulta; em seguida, foram marcados por traços de rebeldia e transgressão que, também transitórios, justificariam os processos na direção da autonomia. Mais recentemente, a perspectiva sócio-histórica demarca a adolescência, a partir dos contextos locais, e conforme os estudos de Bock, Furtado e Teixeira (2001), bem como o de Aléssio e Santos (2005), os adolescentes têm autonomia suficiente para desenvolver-se, inclusive, por meio do trabalho. Portanto, adotamos a perspectiva de que os significados atribuídos à adolescência variam nas práticas socioculturais em que se inserem.
Entendemos que a diversidade de experiências individuais e coletivas dos atletas-adolescentes, a partir da vitória/derrota, dá sentido à realidade social, produz identidades, organiza as comunicações e orienta condutas, como preconizado pela Teoria das Representações Sociais - TRS (Moscovici, 2009), foco psicossocial que permite compreender as trocas comunicativas e suas influências nos modos de ser e agir no mundo.

\section{A teoria das representações sociais}

A TRS permite a compreensão e explicação aprofundada dos fenômenos sociais, por isso, é pertinente para fenômenos complexos. No processo de identificação das RS, elas não se mostram da mesma forma para todos os membros da sociedade, uma vez que os sujeitos se inserem em diversos contextos socioculturais, com crenças, experiências, interações sociais, informações e sentimentos compartilhados. As RS referem-se a este conjunto de atributos que configuram o pensamento social, e nos permite circunstancializar dado objeto. Elas se constituem, portanto, em pontos de encontro do psicológico com o social, pois é a partir dos modelos de pensamentos transmitidos, por meio da tradição, da educação, e da comunicação social que o senso comum se organiza, teorizando o cotidiano.

Segundo Santos (2005), tal teoria do senso comum é um modelo teórico de compreensão e explicação de conhecimentos leigos, isto é, o fenômeno das RS. Entretanto, nem todos os conhecimentos do senso comum são denominados RS, pois precisam se apresentar como um objeto de relevância cultural para o grupo, polissêmico e polimorfo, o que Ihe confere distintos sentidos. Assim, as RS constituem-se em um "[...] meio pelo qual os seres humanos representam objetos de seu mundo" (Lalhou, 2011, p. 66).

Os fenômenos na sociedade são, assim, processados nos grupos em particular, e nas influências desses, na medida em que "[...] o homem se expressa na comunicação e na conduta, e as respostas que encontra a essa 
expressão vão transformando sutilmente a sua própria representação" (Madeira, 1991, p. 140).

Nesse sentido, a TRS busca compreender como determinado grupo constrói um conjunto de saberes que são hierarquizados e influenciam suas condutas e práticas sociais, afinal, faz-se necessário não somente conhecer o conteúdo de uma representação, mas tentar explicar como as pessoas pensam; o porquê deste pensamento; e ainda a forma que ele se organiza e estrutura (Almeida, 2005). Os processos de construção das RS, objetivação e ancoragem, baseiam-se na memória social, em função da realidade presente, e com o apoio de recursos proporcionados pela sociedade e pela cultura (Sá, 2007). A função básica de ambos é tornar familiares objetos desconhecidos (novos), protegendo-os dos conflitos das mudanças e reforçando o sentimento de continuidade e pertencimento.

Na objetivação, segundo Moscovici (2009), os sujeitos compõem imagens reais, concretas e compreensíveis, retiradas de noções abstratas de seu cotidiano, transferindo o que está na mente para algo do mundo físico, de modo a conceituar novos esquemas que se apresentam e com os quais têm de lidar. Sua função social é agir como um facilitador da comunicação, atribuindo a um conceito científico, um significado do senso comum. $\mathrm{Na}$ ancoragem, os sujeitos atribuem sentidos às representações, assimilando as imagens criadas pela objetivação, investigando os valores sociais e sua atribuição de coerência: "É um processo que transforma algo desconhecido e perturbador em algo conhecido, através da comparação com categorias já conhecidas" (Santos, 2005, p. 32-33).

Segundo Abric (1998), para todas as RS existe um núcleo central por estas se constituírem em uma manifestação do pensamento social composto por um número limitado de elementos, e três funções dinâmicas e essenciais: a função geradora, que dá significado à representação; a função organizadora, responsável por explicar como determinados elementos assumem mais relevância e outros menos, permanecendo na periferia; e a função estabilizadora, fixação das RS, que dá ao grupo um sentimento de pertencimento, como no grupo de atletas-adolescentes que trataremos adiante.

\section{Adolescência, natureza, cultura e práticas esportivas}

Na compreensão da adolescência, segundo a Psicologia Sócio-histórica, entendemos que há inter-relação entre as dimensões social, biológica e cultural, o que invalida a demarcação de características inatas ou adquiridas, pois o meio é um constante mediador da ação humana que possibilita, reforça e articula as necessidades dos sujeitos às experiências com as quais ele se envolve, o que inclui a cultura, além de momentos históricos característicos de grupos sociais específicos (Menandro, Trindade \& Almeida, 2010).

Para Ozella (2003, p. 9), a adolescência é demarcada "[...] por tormentos e conturbações vinculadas à emergência da sexualidade, enfim, uma etapa marcada por características negativas, sofridas, patologizadas, que ocorreria necessariamente em qualquer condição histórica e cultural, isto é, universalizada". Tal perspectiva influenciou o senso comum e os instrumentos midiáticos, propagando a ideia da adolescência como uma fase com características fixas, naturalmente constituintes do desenvolvimento humano. A ideia de transitoriedade encerrava marcadores sociais relacionados a um tempo pré-determinado (do final da infância à vida adulta), indispensável, sem maiores distinções em seus aspectos fundamentais (Menandro et al., 2010).

Ozella e Aguiar (2008) acreditam nesta caracterização como uma forma de camuflar os reais motivos pelos quais os adolescentes se sentem em conflito, afinal, cada um é sujeito de sua própria história e, portanto, fará diferentes articulações com os eventos psicológicos produzidos que, por sua vez, também se distinguem de pessoa para pessoa, frente às realidades específicas. Segundo Bock e Liebesny (2003), a situação destes adolescentes demonstra, por meio de seus corpos, 
cognição e afetos, pleno desenvolvimento e autonomia, ou seja, requisitos necessários à sua inserção no mundo do trabalho, por exemplo. Entretanto, não significa necessariamente um lugar no mundo adulto, e esta possibilidade não parece plausível, pois eles carecem de um ritual que os inicie.

A contradição entre as condições dos adolescentes e o consentimento para sua atuação no mundo acarreta uma série de características que podem se refletir, atualmente, em crises e condutas, dentre as quais: rebeldia, conflito geracional, indefinição de identidade e onipotência. Ao adolescente é solicitada responsabilidade, maturidade, cautela nas decisões e atuações, entretanto, mesmo que tais requisitos sejam atendidos, há impedimento para realizar determinadas atividades, com o argumento de que ainda não está "pronto", sendo necessária uma moratória (Calligaris, 2009), tempo de espera para que possa ser considerado independente. Tal concepção, segundo Calligaris (2009), é uma fase de preparação para a vida adulta, influenciada por questões econômicas e o ingresso no mundo do trabalho.

Diversos autores conferem que a adolescência "[...] constituiu-se na história a partir de necessidades sociais e todas as suas características foram desenvolvidas a partir das relações sociais com o mundo adulto e com as condições históricas em que se deu o desenvolvimento" (Bock \& Liebesny, 2003, p. 208). Assim, especificidades históricas e culturais de diferentes grupos sociais sinalizam a forma como esse período é percebido e representado, o que significa dizer que adolescência é uma construção social (Menandro et al., 2010).

Para Ozella e Aguiar (2008), a adolescência é um momento histórico, interpretado e construído pelos sujeitos, os quais mantêm com a sociedade uma relação de mediação constituída mutuamente, tendo suas identidades preservadas, como um ser único, singular e histórico, e

[...] assim, a adolescência é compreendida como um momento de um processo e, como tal, em construção, que pode ser diferente do que está sendo para o próprio adolescente e para uma sociedade. É entendido como não natural e universal, mas produto de sua história de vida, enquanto sujeito pertencente a um grupo social, a uma cultura, da qual recebe influência e sobre a qual age dialeticamente [...] (Fonseca \& Ozella, 2010, p. 413).

A alteridade, nas experiências vividas por adolescentes, se expressa na identificação entre grupos restritos de pares, com quem se reconhecem mediante o compartilhamento de determinadas escolhas de estilos de vida e, assim, se veem também diante de uma lente pela qual leem o mundo. Calligaris (2009), apresenta o adolescente gregário como aquele que "[...] se afasta dos adultos e cria, inventa e integra microssociedades que vão desde o grupo de amigos até o grupo de estilo, até a gangue" (Calligaris, 2009, p. 36). Tais grupos acabam por funcionar como orientadores de condutas, valores e hábitos, afinal, há pré-requisitos a serem contemplados nos modos de ser, seja pela composição de uma imagem corporal ou por outros marcadores que se mostrem evidentes para os demais.

Historicamente, determinados valores e características relacionados diretamente aos esportes se tornam marcadores sociais de seus atletas: um estilo de vida mais saudável, bem-estar físico e o culto a um corpo adaptado àquela prática esportiva; treinamentos específicos e contínuos, nos quais são valorizados tanto o condicionamento físico e a perfeição dos movimentos; número elevado de participações em competições; vivência diferenciada, com vida social restrita, mediante os horários atribulados com compromissos de treinos e competições, bem como o cumprimento de todas as atividades que envolvem o esporte de alto rendimento, marcado pela disciplina rigorosa e metas pré-definidas.

Na cultura atual de ranking do conjunto da sociedade, outros modos de vida têm visibilidade, tais como as vestimentas utilizadas no meio esportivo que assumem, para os atletas-adolescentes, um valor de referência, 
desde aquelas casuais, do cotidiano e treinos, àquelas que são reservadas às competições. Neste sentido, criam-se padrões hegemônicos relativos: "As roupas, os hábitos, as gírias, as grifes são agora 'universais'. Os grupos de jovens nas comunidades locais recebem quase de imediato a informação sobre as referências americanas e européias. As culturas locais são desvalorizadas" (Bock \& Liebesny, 2003, p. 212).

Para os atletas-adolescentes, há uma gama de possibilidades, e ao mesmo tempo de impedimentos, e a prática de um esporte competitivo é percebida como uma unidade integradora de experiências, emoções e atividades. Desta forma, o esporte de alto rendimento circunscreve o desenvolvimento de seus praticantes, pois traz ora ampliação das atitudes e comportamentos, e ora restrição.

Fazendo um paralelo às modalidades de vivência da infância e da adolescência no Brasil, Sampaio (2000) considera que a adolescência atrelada ao cotidiano do esporte de alto rendimento se define como "infância e adolescência públicas", ou seja, uma vida pública precoce por tais sujeitos assumirem relações de trabalho, responsabilidades. Assim, é "[...] uma adolescência glamourosa, cercada de aplausos, fama e dinheiro, mas também, de muita competição, disputa, trabalho, compromissos, desgaste físico e emocional" (Sampaio, 2000, p. 162). No contexto de vida esportiva, o atleta-adolescente é essencialmente disciplinado, meticuloso, e o esporte é um marcador fundamental na dinâmica e construção da adolescência, que traz repercussões nas práticas sociais e no âmbito da família.

\section{Adolescência, famílias e práticas esportivas}

A preocupação com resultados se aplica a busca incessante pelo sucesso, seja este na escola, como o melhor aluno da turma; no vestibular, com a concorrida vaga; ou no trabalho, com o salário mais alto (Korsakas, 2002). Desse modo, a prática dos esportes sofre severas influências do modelo social produtivista, bem como a infância e adolescência também, agora com múltiplas exigências para crianças e jovens. Korsakas e De Rose Junior (2002) relatam ser cada vez mais frequente a reprodução do modelo de treinamento esportivo, destinado ao esporte profissional, nos programas que envolvem crianças e adolescentes, o que é bastante preocupante ao seu desenvolvimento, tendo em vista as consequências de níveis físicos, psicológicos, motrizes e esportivos que a especialização esportiva precoce possibilita.

Para Corsaro (2011), a família tem importante papel no processo de desenvolvimento, por exercer influências na vida da criança e do adolescente. Assim, a estrutura e o cotidiano familiar podem contaminar, contagiar e afetar negativamente a vida desses sujeitos. Os pais apresentam a função social de segurança, apoio e cuidado para o atleta-adolescente, como um suporte estruturante, contudo, na atualidade, esta prática torna-se coerente com os valores da sociedade competitiva, na busca dos lugares de sucesso para os seus filhos.

Este é um desafio adicional para os pais, pois, nas práticas esportivas, os riscos físicos envolvem lesões ósseas, articulares, musculares e cardíacas; nos aspectos psicológicos, altos níveis de ansiedade, estresse, frustração, sofrimento psíquico devido às derrotas e desilusões; e, ainda, formação escolar deficiente.

A prática intensa de uma modalidade específica ainda pode causar limitação de determinados movimentos e exercícios, bem como o burnout, que levaria ao abandono do esporte como uma reação ao estresse e às situações vivenciadas cujas recompensas são inferiores aos gastos físicos e psicológicos dos participantes (Samulski, 2002). Entretanto, quando realizada de modo adequado, a prática esportiva apresenta contribuição efetiva na formação de seus atletas, afinal, relações interpessoais são possíveis mediante a sua realização.

Segundo Epiphanio (2002), podem ocorrer ganhos cognitivos quando o adolescente assimila informações evocadas por meio de uma orientação, desenvolvendo, assim, a sua capacidade de abstração e ampliando o seu vocabulário. No aspecto psicológico, 
vitórias e derrotas oportunizam lidar com experiências que envolvem autoconfiança, autoestima, autoimagem e controle emocional, como uma espécie de "preparação" para outras situações da vida cotidiana que, certamente, enfrentarão ao longo da vida pessoal e profissional futura.

Os sentimentos e emoções vivenciados no esporte parecem estar intimamente vinculados à condução dessas práticas, tanto por parte dos treinadores e familiares, quanto por parte da organização e dinâmica do esporte de alto rendimento, pois quanto maior o nível, há redução do caráter lúdico da atividade. Não estamos afirmando, aqui, que não é saudável a participação de crianças e adolescentes em competições, afinal de contas, são sujeitos que fazem parte de uma sociedade extremamente competitiva, porém, cabe ter clareza dos efeitos positivos e negativos que a prática competitiva oferece.

\section{Método}

No estudo, adotamos a perspectiva plurimetodológica, que permitiu escolher diferentes recursos de coleta e análise de dados. A escoIha das modalidades esportivas teve como critério assegurar um esporte individual e outro coletivo e, assim, optamos pela natação e pelo vôlei, por serem também dois esportes de ascensão social, com visibilidade perante a mídia e o público, e com algumas semelhanças, tais como: títulos mundiais, olímpicos, e atletas reconhecidos como ídolos.

A fase empírica da pesquisa foi dividida em duas etapas, com o aprofundamento e o refinamento progressivo das informações pelos participantes (Cruz, 2006). Na primeira etapa, participaram 101 atletas, dos sexos feminino e masculino, e faixa etária entre 12 e 18 anos de idade. Nesta fase, os sujeitos escreveram no Questionário de Associação Livre-QAL, cinco palavras que associavam quando liam cada expressão-indutora, vitória para os pais/derrota para os pais e, "[...] a espontaneidade das respostas, sem maiores explicações e/ou censuras [...]" (Cruz, 2006, p. 145), definiu o campo semântico das RS. Na análise dos QAL, as palavras foram quantificadas e classificadas por categorias temáticas, de acordo com a similitude semântica. Construímos quadros com estas palavras e o respectivo quantitativo de evocações, fornecido pelo software EVOC, e atribuímos ao termo de maior número de evocações, a denominação de cada categoria.

Na segunda etapa, as palavras mais recorrentes de cada categoria temática subsidiaram as entrevistas individuais e tal devolução dos resultados aos participantes permitiu um trabalho de construção realizado em coautoria (Cruz, 2006). Realizamos cinco entrevistas apresentando aos participantes os dados analisados da primeira etapa, mostrados em uma cartela, e solicitamos que explicassem o porquê das escolhas. Nas análises das entrevistas, utilizamos as técnicas de análise temática de conteúdo de Bardin (2004).

\section{Resultados e discussão}

Embora as expressões-indutoras tenham sido analisadas separadamente, optamos por apresentar os resultados conjugando-as, porque elas se complementam. Na expressão indutora vitória para os pais revelaram-se duas dimensões: dimensão afetivo-emocional e dimensão pessoal e motivacional, e o sentido de vitória foi ampliado para outras condições de vida, distanciado das práticas esportivas e relacionado aos estudos e ao mundo do trabalho: passar de ano, ser aprovado no vestibular, passar em concursos públicos, concluir um curso superior e possuir um emprego. Na derrota para os pais, surgem as duas dimensões anteriores e também a dimensão técnica. Começamos, por este achado, a compreender o sentido subjetivo atribuído à vitória, enquanto na derrota há a autoculpabilização para superar marcas.

A dimensão afetivo-emocional evidenciou na vitória emoções e sentimentos positivados que os atletas-adolescentes atribuem aos seus pais: felicidade, alegria, emoção, animação e empolgação que sugerem sentidos de comemoração e satisfação com o desempenho dos filhos. Já na derrota para os pais foram evidenciados emoções e sentimentos negativados: tristeza, choro, desânimo e desespero, 
que denotam sentidos de infelicidade e insatisfação com a derrota dos filhos e, por conseguinte, descontentamento que gera reclamações, críticas e conflitos.

Segundo Bock et al. (2001), a família é idealizada como um lugar de proteção e cuidado. Nesse sentido, as práticas dos pais, relacionadas ao esporte de alto rendimento, são compreendidas pelos filhos (atletas-adolescentes) como cuidado natural da função parental cotidiana, e não como uma valorização da prática esportiva. Todavia, os atletas-adolescentes começaram a expressar a crença de que o sucesso nos esportes não é um valor para os pais, pois a preocupação deles seria relacionada ao futuro, isto é, aos estudos e a vida profissional dos filhos. Vale salientar que, no cotidiano, esses pais demonstraram práticas de cuidado afetivo, percebidas no campo de pesquisa, por meio do acompanhamento em treinamentos e competições, bem como mediante a preocupação com a bebida e alimentação antes e depois dos treinos, embora estas sejam secundarizadas em seu valor, por serem transitórias, quando comparadas com os estudos, interpretados como base para toda a vida dos filhos.

Vale salientar, que o caráter do filho apareceu como vitória para os pais, pois está relacionado à educação que recebeu e seus princípios morais. Segundo os atletas-adolescentes, os pais esperam que se eles tornem boas pessoas, que estejam fora das drogas, dispostos a ajudar os outros. Ou seja, os esportes contribuiriam na formação dos filhos, como proteção aos perigos externos e aprendizagem de valores solidários, vistos, então, como vitória, em uma sociedade tão competitiva, como explicitado na entrevista: "Acho que eles se sentem vitoriosos no caráter porque veem que tem uma boa criação, veem que o filho tem bom pensamento, e procura ser uma pessoa de caráter bom" (Vôlei Feminino).

Dentre os projetos de vida que os filhos acreditam que os seus pais constroem para eles, como vitórias na vida, destacam-se a construção da família e a conquista de independência, o que também pode expressar o próprio desejo destes adolescentes projetado na sua família. Este achado confirma Amazonas (2010), quando discute que a profissionalização permite a inserção dos sujeitos no mundo do trabalho, embora todas as suas conquistas revelem o sentido do adolescente em construir a sua família.

Na dimensão pessoal e motivacional, o sentido da vitória é de dever cumprido, pois vencer, se relaciona ao sucesso, ícone do esporte de alto rendimento reforçado pelos treinadores, mídia e público em geral. Segundo Rúbio (2001), desde a Grécia Antiga era dado valor diferenciado àqueles que ali venciam e, nos dias de hoje, também não é diferente, pois com a competitividade exacerbada, os campeões são muito exaltados, assumem um lugar de superioridade, e a vitória parece ser, de fato, o que há de mais importante. Na derrota, os atletas-adolescentes atribuem que seus pais a designam como: preguiça, falta de vontade, irresponsabilidade, insegurança, falta de estímulo, corpo mole e distração, sinônimas de reprovação, não estudar, ser um péssimo aluno e falhar na vida acadêmica. Nesse sentido, a derrota é também ampliada para outras situações, além do esporte, relacionadas à vida escolar e características pessoais.

Nesta dimensão, os atletas-adolescentes descreveram a vitória com entusiasmo, e acreditam que ela é compartilhada por seus pais, objetivada na concretude do afeto com carinho e abraços. Os pais reconhecem a conquista, o esforço, o comprometimento, a dedicação e determinação durante $\mathrm{o}$ treinamento. Na derrota, os pais também expressam afeto, prestam apoio e consolo aos filhos, no sentido de ajudá-los e acoIhê-los, incentivando-os a não perder a fé, erguer a cabeça, dar a volta por cima e agir com positividade, pois acreditam que eles certamente terão novas chances para vencer. Outros atributos também foram relacionados: confiança, coragem, concentração, garra, metas. Emergiu, ainda, uma imagem de atleta ideal, com características individuais, habilidades e comportamentos. Tais requisitos parecem disseminados no senso comum, e contribuem na construção da ideia de qual 
estilo de vida esportiva é necessário para obtenção de uma carreira vitoriosa.

$\mathrm{Na}$ análise estrutural das RS de vitória para os pais, o quantitativo de 443 evocações apresenta 146 palavras diferentes, e o significado geral é de orgulho, que apareceu de modo significativo, com frequência diferenciada entre os sujeitos, também com maior importância na hierarquização. Na estrutura das RS de derrota para os pais foram associadas, no campo semântico, 409 palavras, dentre as quais 189 diferentes. O núcleo central é constituído por sentimentos negativados como decepção e infelicidade, como repercussão que os atletas-adolescentes imaginam que é a derrota para os seus pais, compatíveis com o que eles sentem nos momentos de derrota, por esperarem outros resultados.

No núcleo central das RS de vitória para os pais, o orgulho aparece atrelado à alegria, com o sentido positivado de satisfação, como se o objetivo tivesse sido atingido. $\mathrm{O}$ sentimento de amor se faz presente, indicando o vínculo familiar de sentido afetivo entre pais e filhos. Estudar também apareceu como sinônimo de vitória para os pais e, segundo Trindade e Souza (2009), desde muito cedo, as crianças aprendem que a escola é o meio para trilhar um bom caminho profissional e ter futuro.

É verdade que as instituições têm grande relevância na concretização desse aprendizado, entretanto, podemos afirmar que, nesse contexto, os filhos apareceram recebendo o apoio constante dos pais. O núcleo central apareceu protegido de mudanças nas RS, no sentido de esforço, superação, motivação, dedicação, determinação e força de vontade, que sinalizam o comprometimento dos atletas-adolescentes na garantia da vitória para os seus pais.

Segundo os atletas-adolescentes, sucesso para a vida do filho não está restrito apenas ao esporte, pois, como vimos no QAL, os estudos se relacionam ao crescimento na vida pessoal e profissional: "Sucesso é bom também, os seus pais ficam super orgulhosos porque o seu filho vai ter o que? Sucesso. Tá ali, tá vendo... poxa, tá vendo que tá crescendo, crescendo na vida" (Vôlei Feminino). Assim, vida escolar e profissional dos atletas-adolescentes, no pensamento social, se relaciona à escolarização com êxito e sucesso profissional para os projetos de futuro. As entrevistas revelaram os estudos como vitória porque permitem a inserção na vida laboral, dada a falta de garantias do esporte de alto rendimento, conforme verificamos no seguinte recorte de entrevista: "Todos os pais falam assim: tem que se concentrar no esporte, mas também tem que se concentrar no estudo, não tá só na... os pais sempre dão apoio, a maioria dos pais sempre dão apoio, mas também sempre querem que você dê alguma coisa em troca, nos estudos, porque muitos atletas não vão conseguir sucesso talvez no esportivo... "(Vôlei Masculino).

A mesma dedicação aos esportes é cobrada para os estudos, pois os pais exigem dos filhos não só nas piscinas e nas quadras, mas também na sala de aula. Quando na vitória os pais focaram a escolarização, entendemos indiretamente que derrota para os pais, na visão dos filhos, é tirar nota baixa e reprovar de ano. Nas entrevistas, interpretamos que eles reconhecem o valor da prática esportiva, bem como o sucesso nesse meio, inclusive, emergiu, ainda, a escola secundarizada, dada a dedicação acentuada (e necessária) ao esporte em seu cotidiano.

Nas entrevistas, as palavras associadas à expressão indutora vitória para os pais fortaleceram em intensidade os sentimentos positivados. A palavra felicidade, foi quantitativamente mais representativa e expressa a conquista e a vibração junto com os filhos, como recompensa pelo esforço, conforme se interpretou na fala de uma atleta-adolescente: "Eles ficam felizes em saber que os filhos conseguiram aquilo que queriam, se esforçaram... e eles ficam felizes com isso" (Natação Feminino). Nessa passagem da entrevista, a felicidade dos pais parece diretamente relacionada à felicidade do filho. Contudo, os próprios atletas-adolescentes veem o valor diferenciado dado à conquista que resulta em medalhas, símbolos das vitórias: "Pros pais é sempre uma felicidade ver o filho vitorioso, chegar com uma medalha em casa. Poxa, é bom... é a maior felicidade" (Natação Masculino). 
Mesmo que o sentimento seja de orgulho, que acompanha a felicidade pela vitória do filho, pareceu-nos que há certa pressão experimentada para que os pais se sintam satisfeitos com os seus resultados, como mostrou outro atleta-adolescente:

Felicidade qualquer vitória vai lhe trazer. Claro que todo mundo quer, principalmente atletas de escola, desse nível, tem essa vontade de mostrar pro pai que é bom, que conseguiu várias coisas, então você sempre fica com esse peso nas suas costas, então, você fica muito feliz quando você conquista algo assim (Vôlei Masculino).

A necessidade do atleta-adolescente em mostrar aos pais sua capacidade, que é "bom em algo", se mostrou evidente nos discursos dos participantes, sinalizando prontidão e autonomia para lidar com as situações do esporte de alto rendimento e, de forma ampliada, com a vida. No caso, eles demonstraram o desejo de satisfazer aos pais, bem como de mostrar a eles, por meio das práticas do cotidiano esportivo, que estão "prontos" para a vida adulta, e se responsabilizam pelos seus resultados, sejam vitórias ou derrotas.

A ideia de satisfazer aos pais, por meio dos resultados, pareceu-nos retribuição pelo esforço dos pais, o cuidado, sua formação como pessoa, como verificamos na seguinte fala:

É... meio que você tenta se esforçar, até porque pra você conseguir a vitória pros pais, tal, até porque eles também cuidaram de você a vida toda, eles também se esforçaram pra criar você, pra lhe dar a melhor educação que eles podiam the dar e tal. Então, você sempre sente essa vontade de dar o que você tem pra mostrar pra eles que você é bom e tal (Vôlei Masculino).

Então, o sentido simbólico de vitória parece uma "oferenda aos pais", para retribuir ou provar algo, o que nos revela o impacto pela responsabilidade para obter vitórias, na subjetividade dos atletas-adolescentes. Outra atleta-adolescente complementa este sentido de "prestação de contas" ou pagamento de dívidas aos pais:
Os pais se esforçam muito também.. como é... a gente também tem que se esforçar porque eles falam: motivação... ficam no pé... não, você tem que melhorar nisso, tem vez que vão em jogo e ficam: poxa, você também tem que fazer isso, tem que falar mais, se esforçar mais, esses negócios (Vôlei Feminino).

O significado é de retorno pelo investimento afetivo e financeiro, tendo em vista que a trajetória esportiva de um atleta do alto rendimento tem início cedo, na maioria das vezes, ainda na infância, conforme verificado na literatura (Weinberg \& Gould, 2008), bem como, é dispendiosa pelo tempo de prática das modalidades dos participantes da pesquisa. Pareceu-nos que os pais acompanham essa história, por vezes, de modo distante, em outras, próxima, mas, em ambas as formas, há um custo financeiro que é desprendido. Talvez dependendo do esforço dos pais por este investimento e de suas histórias de vida, tem-se distintos sentidos, alguns dos atletas-adolescentes revelam sentir cobrança concreta dos pais em relação às suas performances esportivas, enquanto, para outros, "Se esforçar muito já é uma vitória. Ter se esforçado e ter tido uma consequência disso boa" (Natação Feminino).

Nos relatos dos atletas-adolescentes, o envolvimento dos pais com a vida esportiva de seus filhos, tornou-se evidente também por meio de atitudes de cobrança por resultados, nas quais interpretamos alto nível de projeção envolvido. Outro atleta-adolescente atribui a este sentimento, o merecimento e a disciplina na trajetória de treinamentos, quando diz:

Pelo menos eu acho que depende do seu esforço, se eles verem que você fez tudo o que você podia, que você foi disciplinado, deu o máximo que você teve, aí vão mais tentar lhe apoiar e... agora se eles verem que você foi descompromissado, sem querer nada com nada e perder, eles vão ter raiva... vão brigar com você assim, até... pô, você tem que dar o seu melhor pra você conseguir chegar lá e tal. Aí eles vão brigar e tal (Vôlei Masculino).

Tais brigas, como revelou este atleta-adolescente, tendem a ocorrer quando há uma percepção de que a performance do 
filho poderia ter sido melhor caso este tivesse demonstrado mais empenho, conforme uma atleta-adolescente afirmou em sua entrevista: "A preguiça de treinar né? É o que os pais mais reclamam... depois, a desculpa é que você perdeu porque você tava com preguiça, aí é um problema" (Vôlei Feminino). Assim, os pais teriam uma idealização de atleta como projeção do filho ideal, cuja dedicação nos treinamentos o faria vitorioso. O sentido de sucesso, por um lado, está relacionado a vida esportiva e, por outro, traz um sentido mais amplo, que se relaciona à situação de esforço e empenho nas competições, bem como a realização do filho idealizado.

$\mathrm{Na}$ estrutura das RS apareceram, apoio e estímulo, como elementos do núcleo central, o que confere ambivalência às condutas dos pais, segundo os filhos, pois, ao mesmo tempo em que estes se sentem decepcionados, infelizes e insatisfeitos mediante a derrota dos atletas-adolescentes, eles os apoiam nesses momentos e lhes dão estímulos para que consigam superar tal situação. Na realidade, a ambivalência diz respeito ao cuidado dos pais em um sentido mais ampliado, pois, ao repassar os valores culturais e hegemônicos de nossa sociedade, prezam que os filhos os sigam (Bock, Furtado \& Teixeira, 2001), e, no esporte de alto rendimento, este valor é a vitória.

Na representação da derrota, a palavra tristeza aparece juntamente à raiva e consolo, palavras com frequência muito significativa, mostrando que a derrota, é uma experiência também difícil e sofrida para os pais. $\mathrm{O}$ núcleo central sugere coerência sentido de apoio afetivo-emocional, com as palavras: conselho e carinho.

A dimensão técnica revelou nas RS da derrota um sentido positivado, de superação, a partir do qual os atletas-adolescentes revelam a necessidade de mais determinação, compromisso, vontade de crescer, treinar mais e coragem para melhorar. Ou seja, precisam demonstrar comportamentos resilientes nas situações de derrota, superação, extraindo ganhos positivos dessas experiências (Castelar-Perim, 2011).
Nas entrevistas, os atletas-adolescentes dizem que a derrota é partilhada entre pais e filhos, como uma experiência de sentimentos negativados, como tristeza, raiva e decepção. Entretanto, o papel social dos pais fica muito claro, na medida em que deles são esperadas condutas de apoio e suporte, como referendado por Bock et al. (2001), em momentos difíceis. Um atleta-adolescente diz:
Meu filho sempre treinou, sempre nadou, sempre se dedicou... quando chega agora, meu filho não consegue atingir o que queria. Uau, isso é real- mente ruim, entende? E é também... eles se entristecem com isso, entende? Mas, no final das contas, o certo seria dar apoio e dizer: meu filho, não se preocupe, na próxima você consegue (Natação Masculino).

Deste modo, os pais continuam a dar apoio, incentivando-os a investir mais nos treinamentos para conquistar o resultado esperado, em outra oportunidade. O fato de o filho ter treinado tanto e os pais, de certo modo, o terem acompanhado nesse processo, faz com que julguem o atleta-adolescente merecedor de uma vitória, como se refere um dos entrevistados: "É que os pais ficam tristes também né, em saber... seu filho treinou tanto né, e não conseguiu" (Natação Masculino).

A raiva também apareceu como sinônimo de derrota para os pais, entretanto, percebemos ambivalência nos sentidos compartilhados pelos atletas-adolescentes, na medida em que abordam esse sentimento por um viés de inconformismo, devido à dedicação que o filho teve para conquistar uma vitória, como no trecho de entrevista: "Raiva porque o filho se dedicou, se dedicou, e não conseguiu aquilo, aí acho que sente meio raiva porque não conseguiu... mas... depois passa, depois eles superam" (Natação Feminino). Além disso, a raiva se faz presente no discurso dos entrevistados quando eles abordaram a insatisfação dos pais com os seus resultados, que deveriam ter sido distintos, como analisamos nas falas: "É... seu pai lhe dá um esporro né, porque você perdeu, que era pra você se esforçar mais... é isso" (Natação Masculino). Deste modo, eles explicitaram a imagem de atleta 
idealizado para continuar pertencendo a este grupo, por isso não se permitem experimentar raiva, e a deslocam para os pais.

Tamanha preocupação em dar "respostas" aos pais, certamente, pressiona e tensiona o atleta-adolescente, "[...] alguns pais botam muita pressão, não é o meu caso, mas eu conheço atletas assim... amigos meus que o pai põe muita pressa em cima dele, pra ele vencer" (Vôlei Masculino), afinal, ele precisa mostrar, por meio de seus resultados, que "é bom" e, assim, satisfazê-los. Em casos de derrota, o atleta-adolescente percebe desapontamento e se responsabiliza, experimentando culpa.

Destacamos, portanto, que, embora os pais, por vezes, exerçam a dupla função parental de cuidado e cobrança, os atletas-adolescentes se veem cobrados e/ou apoiados. Pareceunos, que a ancoragem do atleta-adolescente, "devedor aos pais", revela um movimento de autoria, na reorganização da identidade, que necessita do outro, os pais, para the apoiar. Embora Oliveira (2010), tenha encontrado negatividade da família em relação aos cuidados com seus filhos, os atletas-adolescentes, desse estudo, nos apresentaram uma posição contrária: pais cuidadosos, preocupados, e com expectativas positivas sobre os filhos, tanto nos aspectos desportivos quanto na vida escolar.

\section{Considerações finais}

Nesta pesquisa, investigamos as RS de vitória/derrota para os pais, segundo atletas-adolescentes do esporte de alto rendimento. Entendemos a adolescência circunstanciada aos grupos de pertença específicos, tendo em vista as suas experiências diferenciadas, pelo meio sociocultural com o qual estão envolvidos (Bock \& Liebesny, 2003; Menandro et al., 2010).

A partir dos resultados, vimos que as RS compõem sistemas que se relacionam, pois, ao investigarmos as RS de vitória/derrota para os pais, apareceram RS de filho e de atleta idealizados, o que corrobora a ideia de Moscovici (2009), de que as RS refletem o que circula no senso comum, por intermédio dos processos comunicativos. O senso comum não apareceu fragmentado e sugere, ainda, que não é possível pensar apenas na construção de um objeto social em particular, e sim, que os objetos sociais envolvidos em uma mesma temática formam redes de significados, e nestes, encontram sentidos para atribuir às suas condutas.

No caso do presente estudo, o foco voltouse ao atleta-adolescente do esporte de alto rendimento, exemplos de comprometimento, disciplina e responsabilidade na prática esportiva. O referencial teórico da TRS nos possibilitou analisar que o pensamento social compartilhado neste grupo específico é pensamento classificatório, competitivo, disseminado no senso comum, no entanto, o sucesso não significa ser o melhor, vencer, e sim, ultrapassar os próprios obstáculos no sentido de autossuperação.

A abordagem plurimetodológica nos permitiu a utilização de recursos distintos para a coleta e análise dos dados (Almeida, 2005; Cruz, 2006), o acesso aos elementos centrais e periféricos das RS, e a compreensão dos sentidos compartilhados pelos atletas-adolescentes. Ressaltamos que, embora o estudo seja de natureza qualitativa, realizamos procedimentos quantitativos, para que os achados fossem consolidados. Nesta direção, destacamos, ainda, o significativo quantitativo de participantes (101), que fortaleceu, ainda mais, os resultados apresentados. A escolha das expressões indutoras que compuseram os QAL foi pensada, para identificar como os atletas-adolescentes representam o que os seus pais constroem acerca da vitória/derrota, elementos explicativos de construção da autoimagem de sucesso/fracasso.

No estudo empírico, compreendemos que as RS de vitória/derrota para os pais apresentam sentidos múltiplos e se relacionam tanto à subjetividade, quanto à dimensão técnica do treinamento. O sentido de vitória é ampliado, não apenas no contexto esportivo, mas na escolarização, e no crescimento pessoal para a vida. Na interpretação dos dados, constatamos fragilidade na autonomia em 
processo de investidura, pois, por um lado, os atletas-adolescentes experimentam a autonomia nos projetos de vida, no seu desenvolvimento e, de outra parte, precisam do outro para apoiar esse sentido de autoria. Interpretamos que as práticas de cuidado dos pais são vistas por seus filhos-atletas como naturalizadas da função parental cotidiana e, na entrada no campo, ficou clara a interdependência dos atletas-adolescentes aos seus pais.

A relevância desta pesquisa se justifica pela carência de trabalhos que relacionem o fenômeno do esporte de alto rendimento ao grupo social de atletas-adolescentes, sobretudo quando analisados pela TRS, além do impacto que o esporte de alto rendimento pareceu-nos repercutir na vida dos atletas-adolescentes.

Para o desenvolvimento humano, e no caso dos atletas-adolescentes, a autonomia tem valor diferenciado quando relacionada à disciplina exigida pelo esporte de alto rendimento, pois, certamente, trará repercussões na disciplina da vida acadêmica, bem como nas atitudes dos sujeitos em outros espaços públicos, que, diferentemente da submissão, significa um passo dentro do ordenamento social, inclusive numa perspectiva cidadã, de quem compreende o sistema, respeita as instituições e acata as normas. Além disso, a organização do tempo e as estratégias de enfrentamento utilizadas pelos atletas-adolescentes, diante de situações adversas de derrota, oportunizadas pelo esporte de alto rendimento também trazem aprendizados importantes aos seus praticantes.

Por fim, salientamos que os cuidados dos pais dos atletas-adolescentes de alto rendimento, na contextualização de uma sociedade competitiva e meritocrática, são reformulados, afinal, Ihes é exigido uma gama de investimentos: financeiro, de tempo e de equilíbrio emocional, para lidar com as situações cotidianas de vitória/derrota de seus filhos, iniciadas na infância. Portanto, nas RS de vitória/derrota para os pais, os atletas-adolescentes dizem que o esporte de alto rendimento amplia as funções materna e paterna, pois exige cuidados e investimentos adicionais, para além daqueles atribuídos tradicionalmente aos pais. 


\section{Isabela Amblard}

Doutoranda pela Universidade Federal de Pernambuco, Recife - PE. Brasil. Email: isabela.amblard@gmail.com

\section{Fatima Leite Cruz}

Docente da Universidade Federal de Pernambuco, Recife - PE. Brasil.

E-mail: fatimacruz@yahoo.com

\section{Endereço para envio de correspondência:}

Universidade Federal de Pernambuco, Centro de Educação. Rua Acadêmico Hélio Ramos s/n, sala 1O8-A. Cidade universitária. CEP: 50000-000. Recife, PE - Brasil.

Recebido: 03/02/2014, Aprovado: 13/02/2015. 
Abric, J. C. (1998). L'approache structurale des representations sociales: devéloppements récents (M. F. S. Santos, trad.). In ommunication présentée à la 4iéme Conférence Internacionale sur les Représentations Sociales, Mexico. México, México.

Aléssio, R. L. S., \& Santos, M. F. S. (2005). Desenvolvimento humano e violência na zona rural. In M. F. S. S. Santos, \& L. M. Almeida (Orgs.). Diálogos com a teoria das representações sociais (pp. 77-97). Recife, PE: EDUFPE.

Almeida, A. M. O. (2005). A pesquisa em representações sociais: proposições teóricometodológicas. In M. F. S. S. Santos, \& L. M. Almeida (Orgs.). Diálogos com a teoria das representações sociais (pp. 117-160). Recife, PE: EDUFPE/EDUFAL.

Amazonas, P. B. (2010). Trabalho... é a condição do ser humano na terra: relações entre as representações sociais do trabalho e os processos de subjetivação. Dissertação de Mestrado, Centro de Filosofia e Ciências Humanas, Universidade Federal de Pernambuco, Recife, PE.

Bardin, L. (2004). Análise de conteúdo (3a. ed.). Lisboa: Edições 70.

Bock, A. M. B., Furtado, O., \& Teixeira, M. L. T. (2001). Psicologias: uma introdução ao estudo de psicologia. (13a. ed., 3 tri.). São Paulo, SP: Saraiva.

Bock, A. M. B., \& Liebesny, B. (2003). Quem eu quero ser quando crescer: um estudo sobre o projeto de vida de jovens em São Paulo. In: S. Ozella (Org.). Adolescências construídas: a visão da psicologia sócio histórica (pp. 203-222). São Paulo, SP: Cortez.

Calligaris, C. (2009). A adolescência. São Paulo, SP: Publifolha.

Castelar-Perim, P. (2011). Resiliência e prática desportiva: um estudo realizado com adolescentes brasileiros. Tese de Doutorado, Faculdade do Desporto, Universidade do Porto, Portugal.

Corsaro, W. A. (2011). Sociologia da infância (2a. ed., L. G. Regius, trad.). Porto Alegre, RS: Artmed.

Cruz, F. M. L. (2006). Expressões e significados da exclusão escolar: Representações sociais de professores e alunos sobre o fracasso em matemática. Tese de Doutorado, Centro de Educação, Universidade Federal de Pernambuco, Recife, PE.

Epiphanio, E. H. (2002). Conflitos vivenciados por atletas quanto à manutenção da prática esportiva de alto rendimento. Revista Estudos de Psicologia, 19(1), 15-22.

Fonseca, D. C., \& Ozella, S. (2010). As concepções de adolescência construídas por profissionais da estratégia em saúde da família (ESF). Interface, 14(33), 411-424.

Korsakas, P.(2002). O esporte infantil: as possibilidades de uma prática educativa. In De Rose Junior, D. (Org.). Esporte e atividade física na infância e na adolescência: Uma abordagem multidisciplinar (pp. 11-23). Porto Alegre, RS: Artmed.

Korsakas, P., \& De Rose Junior, D. (2002). Os encontros e desencontros entre esporte e educação: uma discussão filosóficopedagógica. Revista Mackenzie de Educação Física e Esportes, 1(1), 83-93.

Lalhou, S. (2011). Difusão das representações e inteligência coletiva distribuída. In A. M.O. Almeida, M. F. S. Santos, \& Z. A. Trindade,(Orgs.). Teoria das representações sociais: 50 anos (pp. 59-97). Brasília, DF: Technopolitik.

Madeira, M. C. (1991). Representações sociais: pressupostos e implicações. Revista Brasileira de Estudos Pedagógicos, 72(171), 129-144.

Menandro, M.C.S., Trindade, Z.A., \&Almeida, A.M. O. (2010). Gente jovem reunida: representações sociais de adolescência/juventude em textos jornalísticos. Vitória, ES: UFES.

Moscovici, S. (2009). Representações sociais: investigações em psicologia social. (6a. ed., P. A. Guareschi, trad.). Petrópolis, RJ: Vozes.

Oliveira, T. A. N. (2010). Ele nunca demonstrou e de repente...: representações sociais da paternidade segundo as mães de meninas vítimas de violência sexual intrafamiliar. Dissertação de Mestrado, Centro de Filosofia e Ciências Humanas, Universidade Federal de Pernambuco, Recife, PE.

Ozella, S. (Org.). (2003). Adolescências construídas: a visão da psicologia sócio histórica. São Paulo, SP: Cortez. 
Ozella, S., \& Aguiar, W. M. J. (2008). Desmistificando a concepção de adolescência. Cadernos de Pesquisa, 38(133), 97-125.

Rúbio, K. (2001). O atleta e o mito do herói: o imaginário esportivo contemporâneo. São Paulo, SP: Casa do Psicólogo.

Sá, C. P. (2007). Sobre o campo de estudo da memória social: uma perspectiva psicossocial. Psicologia: Reflexão e Crítica, 20(2), 290-295.

Sampaio, I. S. V. (2000). Televisão, publicidade e infância. São Paulo: Annablume; Fortaleza: SEDUC.

Samulski, D. (2002). Psicologia do esporte. Barueri, SP: Manole.
Santos, M. F. S. (2005). A teoria das representações sociais. In Santos, M. F. S., \& Almeida, L. M. (Org.). Diálogos com a teoria das representações sociais (pp.13-38). Recife, PE: EDUFPE.

Trindade, Z. A., \& Souza, L. G. S. (2009). Gênero e escola: reflexões sobre representações sociais e práticas sociais. In A. M. O. Almeida, \& D. Jodelet (Orgs.). Representações sociais: interdisciplinaridade e diversidade de paradigmas (pp. 225-244). Brasília, DF: Thesaurus.

Tubino, M. J. G. (1992). Dimensões sociais do esporte. São Paulo, SP: Cortez.

Weinberg, R. S., \& Gould, D. (2008). Fundamentos da psicologia do esporte e do exercício. (4a. ed., C. Monteiro, trad.). São Paulo, SP: Artmed. 